\title{
Review Article \\ Oxidative Stress-Mediated Skeletal Muscle Degeneration: Molecules, Mechanisms, and Therapies
}

\author{
Min Hee Choi, ${ }^{1,2}$ Jin Rong Ow, ${ }^{1,2}$ Nai-Di Yang, and Reshma Taneja, \\ ${ }^{1}$ Department of Physiology, Yong Loo Lin School of Medicine, National University of Singapore, Singapore 117597 \\ ${ }^{2}$ NUS Graduate School for Integrative Sciences and Engineering, National University of Singapore, Singapore 117597 \\ Correspondence should be addressed to Reshma Taneja; phsrt@nus.edu.sg
}

Received 21 July 2015; Revised 8 October 2015; Accepted 8 October 2015

Academic Editor: Gabriele Saretzki

Copyright (c) 2016 Min Hee Choi et al. This is an open access article distributed under the Creative Commons Attribution License, which permits unrestricted use, distribution, and reproduction in any medium, provided the original work is properly cited.

\begin{abstract}
Oxidative stress is a loss of balance between the production of reactive oxygen species during cellular metabolism and the mechanisms that clear these species to maintain cellular redox homeostasis. Increased oxidative stress has been associated with muscular dystrophy, and many studies have proposed mechanisms that bridge these two pathological conditions at the molecular level. In this review, the evidence indicating a causal role of oxidative stress in the pathogenesis of various muscular dystrophies is revisited. In particular, the mediation of cellular redox status in dystrophic muscle by NF- $\kappa \mathrm{B}$ pathway, autophagy, telomere shortening, and epigenetic regulation are discussed. Lastly, the current stance of targeting these pathways using antioxidant therapies in preclinical and clinical trials is examined.
\end{abstract}

\section{Sources of Reactive Oxygen Species}

Reactive oxygen species (ROS) are highly reactive oxygencontaining molecules that are natural by-products of eukaryotic cellular metabolism $[1,2]$. Primary sources of ROS in cells are the membrane-bound NADPH oxidase complex and the electron transport chain (ETC) in the mitochondria [14]. NADPH oxidase is a protein complex that is comprised of a membrane-bound NOX protein, $\mathrm{p} 22^{\text {phox }}, \mathrm{p} 47^{\text {phox }}, \mathrm{p} 67^{\text {phox }}$, $\mathrm{p} 40^{\text {phox }}$, and the small GTPases Racl or Rac2. There are five homologues of the NOX protein, each of which shows distinct tissue-specific expression patterns. For instance, NOX1 is expressed in the colon, smooth muscle, and placenta, while NOX2 is expressed in phagocytes, skeletal muscle, and neurons [3]. Upon activation, NADPH oxidase utilizes NADPH as an electron donor to produce the ROS superoxide $\left({ }^{\circ} \mathrm{O}_{2}{ }^{-}\right)$ [3]. In contrast, production of ROS at the mitochondrial ETC is an unintended consequence of inefficiencies in the transfer of electrons between the complexes. The major sites of ROS leakage are believed to be complexes I and III, although other components of the ETC also have considerable contribution to the overall amount of ROS produced at the mitochondria [4]. Given that excessively high amounts of intracellular ROS have dire repercussions, it is unsurprising that each step of ROS generation is tightly detoxified by a line of antioxidant enzymes. For example, ${ }^{\circ} \mathrm{O}_{2}{ }^{-}$is converted to hydrogen peroxide $\left(\mathrm{H}_{2} \mathrm{O}_{2}\right)$ by the antioxidant enzyme superoxide dismutase (SOD). $\mathrm{H}_{2} \mathrm{O}_{2}$ is then reduced to water either by glutathione peroxidase or catalase. Glutathione peroxidase is a cytoplasmic selenoprotein that reduces $\mathrm{H}_{2} \mathrm{O}_{2}$ as well as other hydroperoxides to water by oxidizing reduced glutathione (GSH) to oxidized form (GSSG) [5]. Catalase is a ubiquitously expressed protein mainly localized in peroxisomes and it is able to reduce $\mathrm{H}_{2} \mathrm{O}_{2}$ efficiently [6]. Apart from the ETC, monoamine oxidases (MAO) in mitochondria also participate in substantial ROS production. MAO catalyzes oxidative deamination of neurotransmitters, dietary amines, and $\mathrm{H}_{2} \mathrm{O}_{2}$ [7]. Reactive nitrogen species (RNS) also contribute to cellular oxidative stress. Nitric oxide synthase (NOS) converts L-arginine to L-citrulline and generates nitric oxide ( $\left.{ }^{\circ} \mathrm{NO}\right) .{ }^{\circ} \mathrm{NO}$ is required for various signaling pathways such as stimulation of guanylate cyclase to increase cyclic GMP (cGMP) production. Nevertheless, ${ }^{\circ} \mathrm{NO}$ is able to react with ${ }^{\circ} \mathrm{O}_{2}{ }^{-}$to produce highly reactive peroxynitrite $\left(\mathrm{ONOO}^{-}\right)$ and induce oxidative stress injury [8].

Emerging evidence suggests that ROS mediate several intracellular signaling pathways required for physiological functions [9]. However, excess ROS production, either due to 


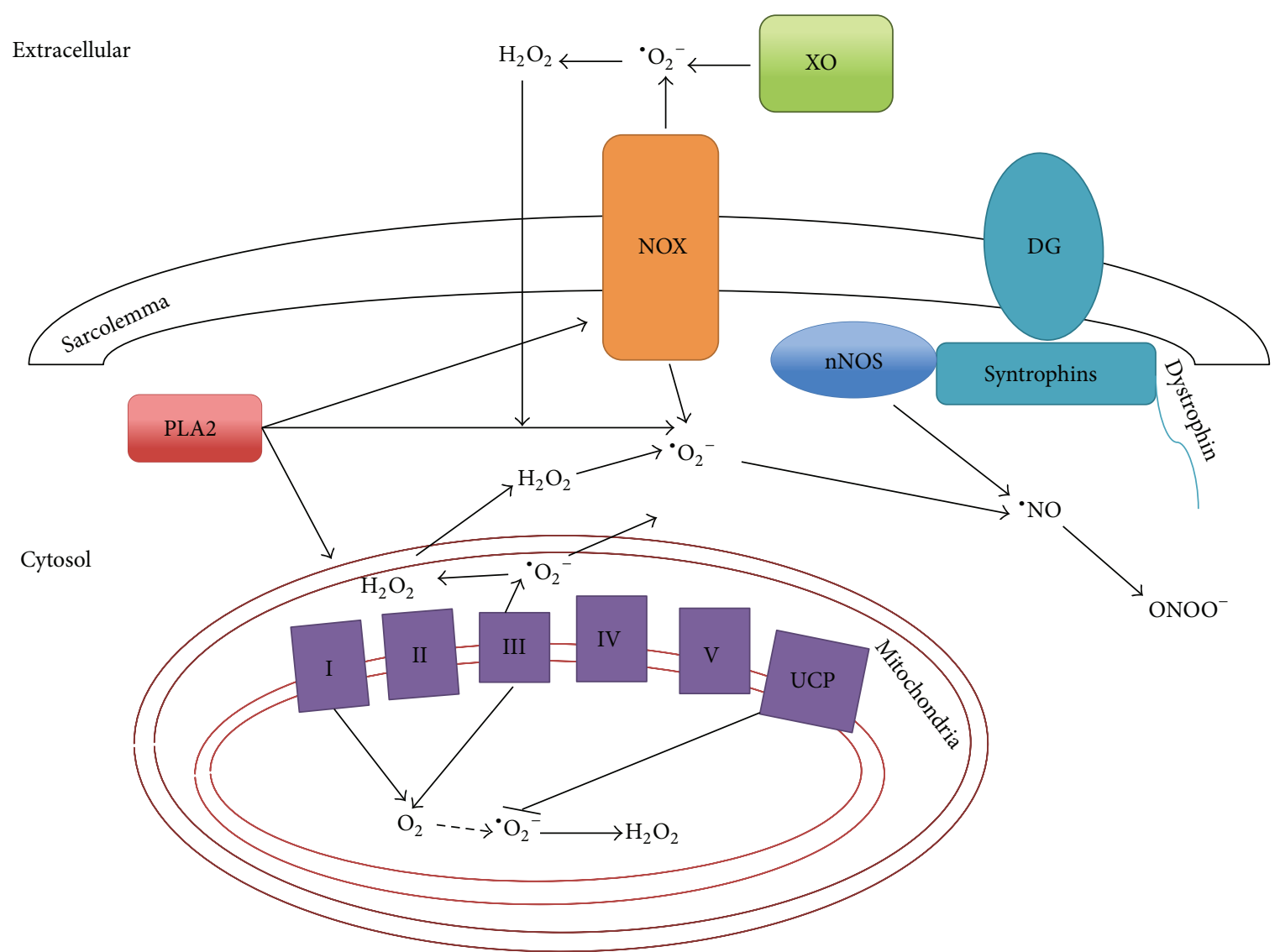

FIgURE 1: Multiple sites of ROS and RNS production are present in skeletal muscle cells. The network of different proteins that leads to ROS/RNS production in the extracellular, cytosolic, and mitochondrial compartments of skeletal muscle cell is illustrated. XO: xanthine oxidase; NOX: NADPH oxidase; DG: dystrophin-glycoprotein; nNOS: neuronal nitric oxide synthase; PLA2: phospholipase A2; I-V: complexes of electron transport/oxidative phosphorylation; UCP: uncoupling protein; $\mathrm{O}_{2}$ : oxygen; ${ }^{\circ} \mathrm{O}_{2}{ }^{-}$: superoxide; $\mathrm{H}_{2} \mathrm{O}_{2}$ : hydrogen peroxide; ${ }^{\circ} \mathrm{NO}$ : nitric oxide; $\mathrm{ONOO}^{-}$: peroxynitrite.

overproduction of ROS or failure to remove them by cellular antioxidant defenses, is one of the detrimental attributes in various human pathologies such as ischemic disorders, cancer, degenerative diseases, and cellular aging [2, 7-12].

\section{Topography of ROS Production in Skeletal Muscle}

ROS have long been associated with both physiology and pathology of skeletal muscle. Production of ROS promotes muscle adaptation to exercise [13]. ROS are generated at multiple subcellular locations in skeletal muscle (Figure 1). Like other nonmuscle tissues, mitochondrial ETC complexes I and III are considered to be the major sites of ROS production in skeletal muscle [4]. Upon contraction, a 100-fold increase in total mitochondrial oxygen consumption only leads to 2- to 4-fold increase in total ROS production [14]. This is partly attributed to attenuation of mitochondrial ROS production by the uncoupling proteins (UCPs) [15], but it also implicates the presence of other ROS production sites apart from mitochondria. Potential nonmitochondrial sources of ROS production in skeletal muscle contraction include NOX,
Xanthine oxidase (XO), Phospholipase A2 (PLA2), and NOS. NOX2, the main NOX isoform expressed in skeletal muscle, is located within the sarcoplasmic reticulum, transverse tubule, and the sarcolemma of skeletal muscle [16]. In particular, inhibition of NOX activity in isolated skeletal myofibers significantly reduces exercise-induced cytosolic ROS production [17]. XO produces ROS as by-products of hypoxanthine oxidation. However, its relevance to human skeletal muscle is still debatable, as XO is not located in skeletal myofibers, but in endothelial cells that make up the blood vessels within skeletal muscle [18]. PLA2 contributes to elevation of ROS in skeletal muscle by (i) catalyzing production of arachidonic acid by ROS-producing lipoxygenases [19], (ii) promoting the translocation of NOX to the sarcolemma [20], and (iii) increasing ROS production in mitochondria [21]. Both calcium-dependent and calcium-independent isoforms of PLA2 participate in ROS production in skeletal muscle, but it is established that calcium-dependent PLA2 isoform is the major determinant of ROS production during exercise $[21,22]$. Skeletal muscle also generates RNS, and, like ROS, its levels are elevated during muscle contraction [23]. Neuronal isoform of NOS (nNOS) is regarded as the primary source 
of RNS production in skeletal muscle and is located in cytoplasm and at the sarcolemma of skeletal muscle by forming part of the dystrophin-glycoprotein complex (DGC) [24].

\section{Evidence for Oxidative Stress in Muscular Dystrophies}

Muscular dystrophy (MD) is a collective term that refers to a group of genetically predisposed diseases that result in skeletal muscle weakness and degeneration [25]. Duchenne Muscular Dystrophy (DMD) is the most prevalent MD that affects an estimated 1:3500 males worldwide [26]. In the USA, an estimated 1:6000 boys are affected according to the Centers for Disease Control and Prevention (CDC) [27]. $\mathrm{DMD}$ is characterized by progressive skeletal muscle degeneration leading to early death due to respiratory or cardiac failure. The primary genetic cause of DMD is mutations in the Dystrophin gene resulting in dystrophin deficiency [28]. This in turn disrupts the DGC, resulting in structural destabilization and deregulated signaling, which subsequently lead to apoptotic and necrotic death of muscle cells [29]. Given the progressive nature of the disease, much effort has been put into identifying contributing factors, such as oxidative stress and increased calcium influx that are elevated in dystrophic muscles [11,30-33]. The role of oxidative stress in pathology was implicated early by the observation that muscles from DMD patients contain a higher level of thiobarbituric acidreactive products, which is indicative of lipid peroxidation brought about by oxidative stress. Dystrophic muscles also exhibit enhanced catalase, SOD, and glutathione reductase activity, which are reflective of oxidative stress [34]. In addition, 8-hydroxy-2' -deoxyguanosine (8-OHdG), a marker of free radical damage to DNA, was found to be elevated [33].

The $m d x$ mouse that harbors a point mutation in the Dystrophin gene [35] has been widely studied as a mouse model for DMD. The muscles of $m d x$ mice are histologically normal prior to the onset of necrosis at about 3 weeks of age, after which necrosis, inflammation, and subsequent regeneration ensue. However, unlike DMD patients, muscle damage subsides to a chronically low level by 8 weeks of age in $m d x$ mice, with little impairment to muscle function, and lifespan is moderately reduced [30]. Interestingly, muscles from $m d x$ mice exhibit increased levels of antioxidant enzymes prior to necrosis, indicative of a cellular response to oxidative stress [36]. Moreover, $m d x$ muscles are more susceptible to oxidative stress-induced injury [37]. In agreement, ectopic expression of catalase in mitochondria was shown to increase lifespan and led to a partial restoration of $m d x$ muscle function [38].

On the other hand, the exact contribution of ${ }^{\circ} \mathrm{NO}$ in DMD pathogenesis is unclear. The association of nNOS with the DGC and the consequential loss of membrane localization of nNOS in the $m d x$ mice [39] raise the question of whether NOS-mediated oxidative stress is involved as well. Nevertheless, while several studies implicate correlation between NOS levels and the severity of DMD in different strains of $m d x$ mice [32], prenecrotic $m d x$ muscle fibers exhibit no change in ${ }^{\circ} \mathrm{NO}$-induced nitrotyrosine formation. Moreover, NOS-null mice do not develop any dystrophic symptoms, and neither NOS-null nor $m d x$ mice with ectopic NOS expression show any alteration in oxidative stress susceptibility [32]. Still, increased levels of oxidative stress markers and antioxidant enzyme expression in the $m d x$ mice support the idea that oxidative stress may be causative of muscle degeneration in DMD. Furthermore, other types of MDs also exhibit signs of oxidative stress, which are discussed below.

Facioscapulohumeral muscular dystrophy (FSHD) is associated with the deletion of the D4Z4 macrosatellite repeats on chromosome 4q35, which increases expression of double homeobox 4 (DUX4) [40]. Muscle cells from FSHD patients show increased susceptibility to oxidative stress, augmented lipofuscin inclusions, elevated expression of antioxidant enzymes, and dysfunctional mitochondria [41].

Mutations in Dysferlin give rise to limb-girdle muscular dystrophy type 2B (LGMD2B) and Miyoshi myopathy (MM), as well as distal myopathy with onset in the tibialis anterior muscles. Dysferlin is enriched in the T-tubule of muscle fibers and plays an important role in maintenance of sarcolemma integrity and calcium influx [42]. Dysferlin-null mice exhibit early elevation of reversible thiol oxidation and oxidative stress markers, implicating potential thiol oxidation of myogenic proteins [31].

Mutations in collagen VI causes two distinct MDs [43]: Bethlem myopathy (BM) which has a milder phenotype and Ullrich congenital MD (UCMD), which exhibits a more severe and rapid pathogenesis, thereby leading to an early death. Recent studies on both collagen VI-deficient mice and patients reported the evidence of defective autophagy, MAOdependent oxidative stress, and resultant mitochondrial dysfunction attributing to pathogenesis of BM and UCMD [44].

Laminopathy is a collective term for a spectrum of agerelated human diseases arising from mutations in the LMNA gene that encodes the intermediate filament nuclear lamin. It includes X-linked Emery-Dreifuss muscular dystrophy (EDMD) and sclerosing bone dysplasia [45]. The C-terminal cysteine tail of lamin A functions as a ROS sensor, the loss of which results in oxidative stress-driven premature cellular senescence [46]. Merosin (laminin-2) is located in the basal membrane of muscle fiber, and mutation of laminin $\alpha 2$ chain causes merosin-deficient congenital muscular dystrophy (MDCMD). It is characterized by neonatal muscle degeneration, colocalization of both necrotic and apoptotic signals in the patient muscle fibers, and increased autophagy.

\section{Signaling Mechanisms Exploited by ROS}

Many mechanisms have been proposed to explain muscle degeneration seen in MD. Among these, one of the most championed mechanism entails the loss of calcium homeostasis as a result of calcium influx through ion channels in the membrane [47]. The increase in cytoplasmic calcium is known to then regulate ROS primarily through disrupting mitochondrial function [21,48], and the contribution of 
calcium to the muscular dystrophy pathology has been wellreviewed recently by Burr and Molkentin [49]. Below, we discuss alternative pathways that modulate and are modulated by ROS and how they are involved in muscular dystrophy.

4.1. $N F-\kappa B$ Pathway. NF- $\kappa \mathrm{B}$ is a transcription factor that drives inflammatory gene expression [50]. NF- $\kappa$ B activation occurs prior to the onset of muscular dystrophy in the muscles of $m d x$ mice. Treatment with the antioxidant $\mathrm{N}$ acetylcysteine (NAC) inhibits its activation, suggesting that oxidative stress lies upstream of NF- $\kappa \mathrm{B}$ and drives upregulation of $\mathrm{NF}-\kappa \mathrm{B}$ to contribute to the myopathy in DMD $[51,52]$. Consistent with this notion, treatment of $m d x$ mice with IRFI-042, a synthetic vitamin E analogue, reduced NF$\kappa \mathrm{B}$ DNA binding, $\mathrm{TNF} \alpha$ expression, muscle necrosis, and enhanced regeneration [53]. Stretch-induced muscle damage in $m d x$ muscles can be reduced by NAC treatment via reducing ROS and nuclear NF- $\kappa \mathrm{B}$ translocation [54]. In $m d x ; \mathrm{p} 65^{+/-}$mice, muscle regeneration is improved, and this is correlated with hepatocyte growth factor (HGF) upregulation. Moreover, inhibition of HGF expression reversed the phenotype of $m d x ; \mathrm{p} 65^{+/-}$mice, suggesting that the NF- $\kappa \mathrm{B}-\mathrm{HGF}$ axis contributes to DMD pathogenesis [55]. Elevated $\mathrm{TNF} \alpha$, which activates $\mathrm{NF}-\kappa \mathrm{B}$, was also found in double mutants lacking both dystrophin and Stra13 [56]. $m d x / S_{\text {Stral3 }}{ }^{-/}$muscles were found to undergo oxidative stress-mediated degeneration. The degeneration of muscles was rescued by treatment of mice with NAC, further indicating a causal role for oxidative stress in muscle cell death. Altogether, it appears that oxidative stress-induced muscle degeneration is mediated, at least in part, by NF- $\kappa \mathrm{B}$.

4.2. Autophagy in Muscle Degeneration. Autophagy is an evolutionarily conserved process in which the intracellular proteins and organelles are first engulfed into double membrane vesicles, termed as autophagosomes, and then delivered to lysosome for degradation [57]. Autophagy has been shown to be involved in various biological functions such as starvation adaptation, turnover of unfolded proteins and damaged organelles, cell metabolism, development, immunity, and cell death. Expectedly, emerging studies showed that autophagy also plays roles in the pathology of different human diseases including degenerative diseases, aging, and cancer [58]. Mechanistic or mammalian target of rapamycin complex 1 (mTORC1) and AMP-activated protein kinase (AMPK) are important autophagic regulators: mTORC1 inhibits autophagy via preventing the activation of ULK1, which is essential for the initiation stage of autophagy, while AMPK, a key sensor of cellular energy status to maintain energy homeostasis, has been shown to promote autophagy [59].

Autophagy plays a dual role in muscle homeostasis [60]. On one hand, excessive autophagy induced by overexpression of $\mathrm{FOXO} 3$ in myotubes causes atrophy via enhancing lysosomal proteolysis [61]. On the other hand, autophagy has been shown to be essential for the maintenance of muscle mass, as autophagy deficiency in muscle leads to abnormal mitochondria and muscle atrophy [62]. The role of autophagy in muscular dystrophies is complex. Defective autophagy is observed in DMD, BM, UCMD, and EDMD. In contrast, increased autophagy is detected in MDCMD [63]. Correspondingly, (i) in the $m d x$ mouse, promotion of autophagy either by AMPK activation or by low protein diet ameliorates muscular dystrophy, which may be due to the elimination of defective mitochondria by mitophagy $[64,65]$; (ii) in collagen VI-null mice, forced activation of autophagy by genetic, pharmacological, or dietary approaches is able to rescue the dystrophic phenotype [66, 67]; (iii) while in the laminin $\alpha 2$ chain-null dy3K/dy3K mouse model, inhibition of autophagy improves muscle morphology [68]. This suggests that the contribution of autophagy to pathology in different dystrophies is indeed distinct and that the forces driving muscle degeneration may be fundamentally different. Regardless, in dystrophies whereby impaired autophagy and accumulation of abnormal mitochondria have been found, the underlying mechanisms of how autophagy impairment occurs have not been well investigated. Studies by Pal et al. showed that the downregulation of autophagy in $m d x$ skeletal muscle is caused by activated Src kinase, which is the key regulator of Nox2-mediated oxidative stress [69]. Both pharmacological and genetic inhibition of Nox 2 or Src kinase induce autophagy, reduce oxidative stress, and improve pathophysiological abnormalities in $m d x$ mouse muscles [69, 70]. However, one recent study showed that activation of P2RX7, an ATP-gated ion channel, increases autophagic flux in dystrophic myoblasts and myotubes, which contributes to nonapoptotic cell death [71]. This study is consistent with an earlier finding that inhibition of autophagy via activation of $\mathrm{PI} 3 \mathrm{~K} / \mathrm{Akt} / \mathrm{mTOR}$ pathway ameliorates dystrophic pathology in $m d x$ mice [72].

Interestingly, epigenetic modifications including DNA methylation, histone modifications, and microRNAs have been shown to regulate autophagy [73]. For example, $\mathrm{NAD}^{+}$dependent class III histone deacetylase Sirtuin 1 (Sirt1) positively regulates autophagy via interaction with autophagy genes (Atg5, Atg7, and Atg8) and direct deacetylation of these components [74]. A recent study showed that muscle-specific inactivation of the Sirtl deacetylase domain leads to muscle developmental and regenerative defects [75]. Therefore, Sirt1 may contribute to muscle development through regulating autophagy. Despite these advances, much remains to be understood about the exact function of autophagy in muscle degeneration. In addition, a better understanding of its epigenetic regulation in dystrophies may provide targets for therapeutic intervention.

4.3. Telomere Shortening and Depletion of Satellite Cells. The observation that culturing human fibroblast in low oxygen conditions can extend the in vitro lifespan of the cells by slowing the rate of telomere shortening led to the idea that oxidative stress may contribute to telomere attrition. The telomeric repeat sequence is especially sensitive to oxidative damage, and single-stranded breaks induced by oxidative stress have been associated with telomere erosion [76]. In agreement, accelerated telomere loss is present in conditions of mitochondrial dysfunction where mitochondrial ROS are high [77]. 
Unexpectedly, while it has been shown that telomeres in muscle also shorten as a result of oxidative stress [78], there is no age-dependent loss of telomeres in muscles [79], possibly because the turnover of skeletal muscle is relatively low and satellite cells may not be used for homeostasis in normal uninjured muscle. In contrast, satellite cells in patients of muscular dystrophy are constantly activated for proliferation as a result of the distinctive degeneration-regeneration cycles. Early studies showed that myoblasts isolated from older DMD patients displayed lower proliferative capacity than those isolated from younger patients [80]. This drop in proliferative capability occurred due to replicative aging as a consequence of telomere shortening [81]. In recent times, landmark studies further support the role of telomere attrition in exhaustion of the satellite cell pool in muscular dystrophy. $m d x$ mice lacking telomerase through the removal of the telomerase RNA component mTR, known as the $m d x / m T R$ mice, recapitulate the severity of the dystrophic phenotype seen in humans that is not normally seen in the $m d x$ mouse. The progressive worsening of pathology with age correlates with loss of proliferative capacity caused by telomere erosion in the myoblasts isolated from these mice $[82,83]$. Similarly, reduced telomerase activity is responsible for the decline of the satellite cell pool that leads to the loss of muscle regeneration in the $m d x /$ utrophin $^{-/-}$double knockout mouse [84].

4.4. BMI-1: The Epigenetic Link to Oxidative Stress. Bmi1 is a Polycomb group protein that prevents premature senescence by repressing the INK4A/ARF locus [85]. Of relevance, Bmi-1 controls the activity of metallothionein $\mathrm{MT1}$, an antioxidant protein, in muscle to regulate oxidative stress, and increased Bmi-1 expression in muscle reduces the oxidative modification S-nitrosylation of MEF2C, which is known to inactivate MEF2C [86]. Consequently, loss of $\mathrm{MEF} 2 \mathrm{C}$ function is causative of muscle degeneration [87].

\section{Therapeutic Avenues}

5.1. Physiological Role of ROS in Muscle Adaptation to Exercise. The observation that there was increased ROS production in the muscle of exercised rats by Davies et al. in 1982 [88] had led to the prediction that ROS might have a physiological role in exercise. Much research has gone into understanding this phenomenon, and now we know that ROS play multiple beneficial roles in exercise physiology. ROS can activate AMPK by reducing ATP, resulting in an increase in PGC-1 $\alpha$ expression and activity after acute and long-term exercise [89]. PGC-1 $\alpha$ is a master regulator of metabolic reprogramming that is key in muscle adaptation to exercise [90]. Thus treatment with NAC results in reduced AMPK and PGC- $1 \alpha$ activation leading to lower uptake of glucose in an in vitro contraction model for exercise [91, 92]. Moreover, the elevation of myokine production upon exercise is blunted by treatment with antioxidants [93, 94]. A clinical trial performed by Ristow et al. [95] demonstrated that the beneficial effects of physical exercise mediated by a transient increase in ROS production leading to enhanced insulin sensitivity were abrogated by supplementation of the antioxidants vitamin $\mathrm{C}$ and vitamin $\mathrm{E}$. These studies suggest that in healthy individuals, acute ROS production is required for adaption of skeletal muscle to exercise. However, chronic overproduction of ROS promotes oxidative stress that in turn contributes to a variety of muscular pathologies [96].

5.2. Antioxidant Therapies under Clinical Trials. Despite a prominent amount of evidence indicating a causal role of oxidative stress in the development of MDs, early clinical trials using antioxidants such as nicotinamide (vitamin B), tocopherols (vitamin E), and penicillamine did not bring about statistically significant clinical benefits [11] Pentoxifylline (PTX) is a phosphodiesterase inhibitor with potent anti-inflammatory and antioxidant activity. Although a preclinical study on $m d x$ mice showed significant muscle strength restoration [97], a recent clinical trial using PTX on DMD patients failed to yield any significant improvement on muscle strength and function [98].

One of the caveats for clinical trials using antioxidant therapy in muscle degenerative disorders such as DMD is that increased oxidative stress has to be targeted at very early stage of disease. Evidence of oxidative stress is detected in prenecrotic $m d x$ mice [36]. As evidence accumulates to support that oxidative stress may precede necrotic cell death of muscle, clinical trials using antioxidant therapy should be initiated early to combat oxidative stress. A further point to note is that many antioxidants are nonspecific scavengers, such that they do not target a specific subcellular organelle source of ROS but are only able to remove existing ROS/RNS end products at the cellular level [99]. This is complicated by the physiological role of ROS as inducers of adaptive responses, which suggest that nonspecific targeting of ROS may unnecessarily suppress these cellular responses. This heightens the importance of searching for alternative routes of antioxidant therapy [100].

5.3. Targeting NF- $\kappa B$. Several pharmacological and natural products with antioxidant properties have been tested to combat the effects of elevated oxidative stress through inhibition of NF- $\kappa$ B activity. Treatment of $m d x$ mice with IRFI042 diminished oxidative stress markers, reduced NF- $\kappa$ Bdependent TNF- $\alpha$ expression, and relieved muscle fatigue [53]. Injection of $m d x$ mice with curcumin, a pharmacological inhibitor of NF- $\kappa \mathrm{B}$, improved histology and biochemical DMD features. Notably, inducible NOS (iNOS) levels were reduced in $m d x$ mice, implicating a possible decrease in ${ }^{\circ} \mathrm{NO}$ mediated oxidative stress [101]. Deferoxamine (DFX) is a potent iron-chelating agent that blocks iron-catalyzed ROS production and subsequent oxidative stress, with evidently reduced NF- $\kappa \mathrm{B}$ levels and improved muscle function in $m d x$ mice [102]. Intense physical exercise aggravates muscle necrosis and is correlated with ROS in $m d x$ mice [103]. The antioxidant NAC is effective for curbing NF- $\kappa \mathrm{B}$ expression in $m d x$ mice, as well as ameliorating increased ROS production, protein thiol oxidation, loss of muscle contraction force, and serum creatine kinase (CK) level in $m d x$ mice under prolonged exercise [31, 54]. A similar effect was 
observed when exercised $m d x$ mice showed improved muscle function upon injection with nifedipine, a calcium channel blocker, with a concomitant reduction in mRNA expression of iNOS and NADPH oxidative subunits [104]. Angiotensinconverting enzyme (ACE) inhibitors curb proinflammatory and prooxidant activity of Angiotensin II. Treatment of $m d x$ mice with the ACE inhibitor enalapril conferred a significant resistance to exercise-induced muscle weakening and a reduction in ROS production, improved limb muscle function, and reduced NF- $\kappa \mathrm{B}$ activation [105]. (-)Epigallocatechingallate (EGCG), a polyphenol antioxidant compound from green tea extract, is known to reduce NF$\kappa \mathrm{B}$ activity. Treatment of prenecrotic $m d x$ mice with EGCG diminished expression of the oxidative stress marker lipofuscin and showed delayed necrosis of the extensor digitorum longus muscle $[106,107]$. Melatonin is an endogenous antioxidant that scavenges ROS and RNS to reduce cellular redox status, and melatonin treatment on $m d x$ mice was shown to improve muscle function [108]. In accordance with the preclinical data, 3-month administration of melatonin to DMD patients significantly reduced serum CK level, lipid peroxidation, nitrites, NF- $\kappa$ B-driven inflammatory cascade [109], and curbed hyperoxidative status of erythrocytes in the treated patients [110]. Idebenone is a synthetic derivative of Coenzyme $\mathrm{Q}_{10}(\mathrm{CoQ})$, which is an electron carrier in the mitochondrial ETC; thus it acts as a potent antioxidant and inhibitor of lipid peroxidation by sequestering leaked electrons from the ETC [111, 112]. Initial studies using idebenone on $m d x$ mice showed improved voluntary motion and cardiac function, thereby increasing survival [113]. A recent phase III clinical trial with idebenone improved respiratory function of 31 DMD patients [112], which counteracts the lethal failure of diaphragm muscle. However, this drug is useful only in patients who have not been previously treated with steroids [114].

5.4. Autophagy as a Therapeutic Avenue. Induction of autophagy via inhibition of mTORC1 by rapamycin has been reported to ameliorate dystrophic phenotype in 6-week-old $m d x$ mice [115]. However, because of mTORC1 involvement in muscle regeneration, the potential usage of rapamycin as muscle therapeutics is limited [116]. Nevertheless, rapamycin nanoparticles, which are able to accumulate in the site of diseases, have been used to activate autophagy in $m d x$ mice, and the results showed an improvement in physical performance of both skeletal and cardiac muscle [117]. AICAR (5-aminoimidazole-4-carboxamide-1-D-ribofuranoside), an established pharmacological activator of AMPK, has been used for the treatment of $m d x$ mice. AICAR induces autophagy, enhances diaphragm mitochondria to resist calcium-induced permeability transition pore opening, and improves histopathology as well as muscle strength [64].

5.5. SIRT1 Stimulation. Resveratrol, a natural polyphenol from grapes and red wine, is known to induce SIRT1 expression [118]. Resveratrol treatment in $m d x$ mice reduces nitrotyrosine, expression of NADPH oxidase subunits, and infiltration of fibrotic tissue in a SIRT1-dependent manner
[119], although it may also act through inhibition of the acute inflammatory response to reduce the degenerative process [120].

5.6. Alternative Therapeutic Approaches. An alternative to pharmacological treatment could be direct supplementation of antioxidant proteins. As mentioned above, direct supplementation of melatonin has yielded a significant clinical outcome in DMD patients [109]. Creatine is a downstream product of glycine and arginine and exerts an antioxidant property by quenching aqueous ROS [121]. Creatine treatment inhibited muscle necrosis and enhanced mitochondria respiration capacity in $m d x$ mice [122]. Four months of creatine administration to 30 DMD patients significantly improved their muscle function [123], although it was implicated that the therapeutic effect of creatine may be less effective for older patients [124]. Adenoviral overexpression of catalase in neonatal $m d x$ mice was shown to be effective in reducing muscle impairment at an early phase of the disease [38]. This proposes the feasibility of an alternative genetic approach to combat elevated oxidative stress in DMD and potentially other muscle degenerative disorders. Nevertheless, one of the most significant problems plaguing the use of adenoviral-mediated therapy is the oxidation of the transgene mRNA due to elevated ROS production in dystrophic muscle, which hampers long-term efficacy of existing transgene therapies [125]. This highlights the importance of specialized protocols of transduction to achieve persistent expression in DMD patients. Satellite cell transplantation could be another strategy. Replacement of dystrophic myosatellite cells with Bmi-1 overexpressing satellite cells could be a way to restrain oxidative stress-induced muscle degeneration through MT1mediated cellular proliferation and function [86]. Nevertheless, these alternative approaches of using cell therapy have their own pitfalls and still require technical refinement on cell delivery, minimization of cell death upon transplantation, and cytotoxicity of neighbouring cells in the niche [126].

\section{Conclusion}

Studies from different animal models and patients indicate that elevated oxidative stress could be causative in inducing various signaling pathways which lead to muscle degeneration [11, 30, 31]. Figure 2 illustrates cellular mechanisms that cause excessive oxidative stress to trigger skeletal muscle degeneration in a variety of disorders. In degenerating muscle, increased oxidative stress is seen concurrently with elevated antioxidant enzyme level, probably as a measure to counteract excessive ROS. Important roles of epigenetic regulators such as Bmi-1 and Sirtuins in inducing antioxidant activity are also evident $[86,120]$. Another cellular process that plays a pivotal role in redox homeostasis is autophagy. Aberrant autophagic activity disrupts muscle physiology either due to excessive lysosomal proteolysis or inefficient elimination of defective mitochondria, and correcting defective autophagy reduces oxidative stress [65]. Mitochondria are the major site of cellular ROS production, and various signaling pathways tightly regulate it. Hence deregulation of 


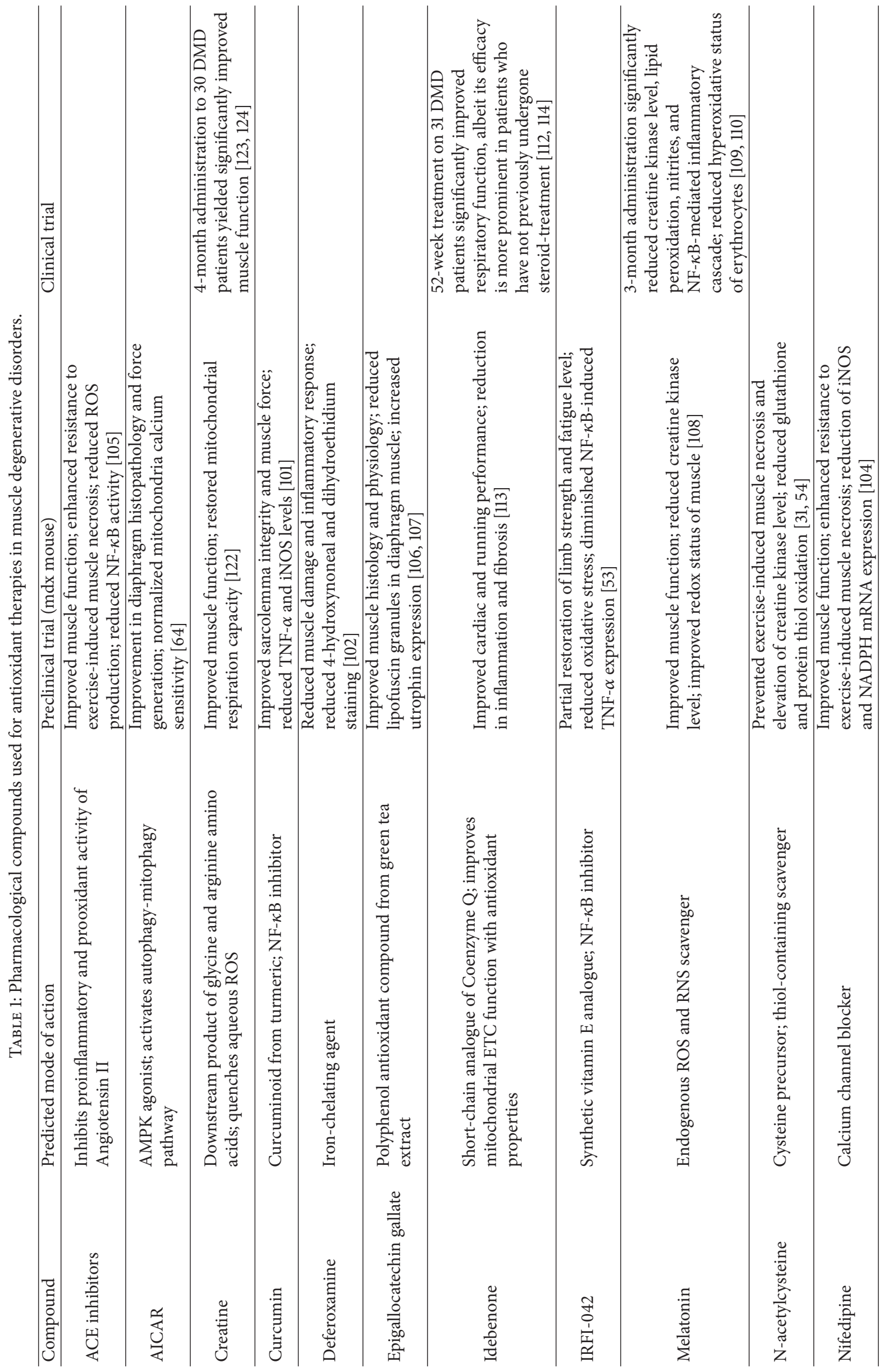




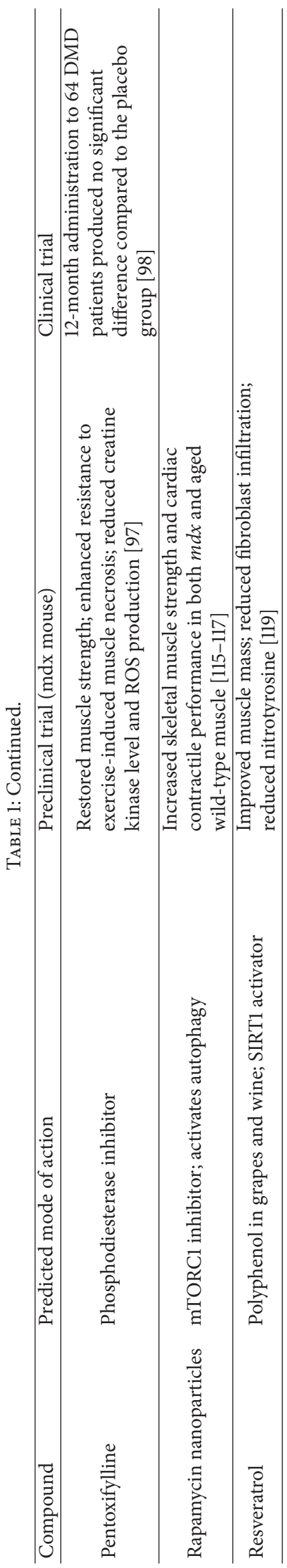




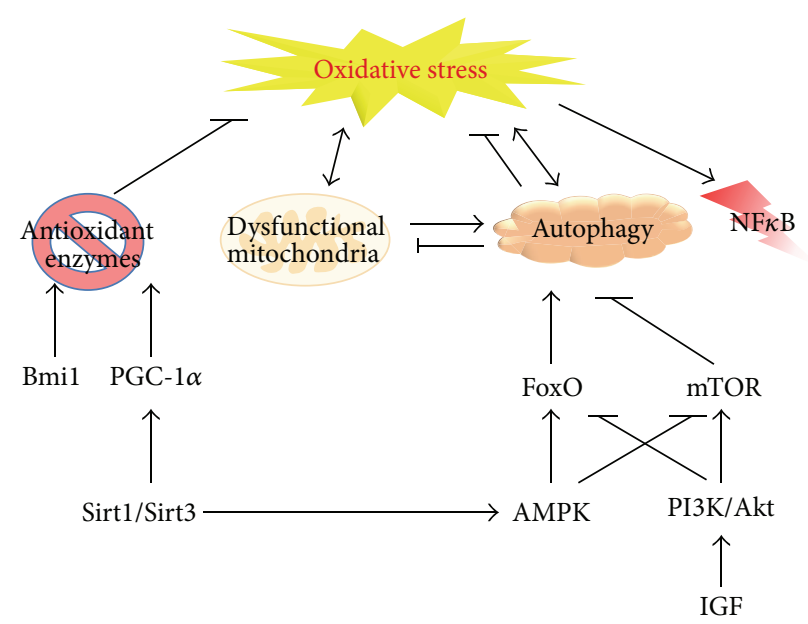

Figure 2: Mechanisms leading to oxidative stress in skeletal muscle. This schematic illustrates cellular mechanisms that are known to exert either prooxidant or antioxidant effects. Aberrant regulation of these pro- and antioxidative processes is indicated to play a role in muscle degenerative disorders. $\mathrm{NF} \kappa \mathrm{B}$ : nuclear factor kappalight-chain-enhancer of activated B cells; Bmil: B lymphoma MoMLV insertion region 1 homolog; PGC- $1 \alpha$ : peroxisome proliferatoractivated receptor gamma coactivator 1-alpha; FoxO: forkhead box O; mTOR: mechanistic or mammalian target of rapamycin; AMPK: adenosine monophosphate-activated protein kinase; PI3K: phosphoinositide 3-kinase; IGF: insulin-like growth factor.

mitochondria plays a critical role in elevation of oxidative stress in degenerative muscle disorders [70]. One of the important downstream events of oxidative stress is activation of $\mathrm{NF}-\kappa \mathrm{B}$ and its consequential inflammatory response, which is a key cellular event that contributes to muscle cell necrosis. These findings have been tested in preclinical and clinical trials to demonstrate their beneficial effects on delay of disease progression in dystrophic patients. Table 1 summarizes pharmacological treatments through antioxidant therapies.

Nevertheless, whether oxidative stress is a causative factor or whether it is simply a by-product of muscle degeneration remains to be established unequivocally. The exact mechanisms through which distinct mutations in various degenerative disorders induce oxidative stress need to be elucidated. With an abundant list of drugs to target oxidative stress, a better understanding of the pathogenesis of the disorders will allow us to make informed decisions on the feasibility of using these drugs to treat dystrophies.

\section{Conflict of Interests}

The authors declare that there is no conflict of interests regarding the publication of this paper.

\section{Acknowledgments}

Work in the Reshma Taneja laboratory is funded by the National Medical Research Council, National University Health System, and the Ministry of Education.

\section{References}

[1] B. Halliwell, "Biochemistry of oxidative stress," Biochemical Society Transactions, vol. 35, no. 5, pp. 1147-1150, 2007.

[2] B. Halliwell and J. M. C. Gutteridge, "Role of free radicals and catalytic metal ions in human disease: an overview," in Methods in Enzymology, vol. 186, chapter 1, pp. 1-85, Elsevier, 1990.

[3] K. Bedard and K.-H. Krause, "The NOX family of ROSgenerating NADPH oxidases: physiology and pathophysiology," Physiological Reviews, vol. 87, no. 1, pp. 245-313, 2007.

[4] M. D. Brand, "The sites and topology of mitochondrial superoxide production," Experimental Gerontology, vol. 45, no. 7-8, pp. 466-472, 2010.

[5] C. Michiels, M. Raes, O. Toussaint, and J. Remacle, "Importance of Se-glutathione peroxidase, catalase, and $\mathrm{Cu} / \mathrm{Zn}-\mathrm{SOD}$ for cell survival against oxidative stress," Free Radical Biology and Medicine, vol. 17, no. 3, pp. 235-248, 1994.

[6] M. Nordgren and M. Fransen, "Peroxisomal metabolism and oxidative stress," Biochimie, vol. 98, no. 1, pp. 56-62, 2014.

[7] N. Kaludercic, J. Mialet-Perez, N. Paolocci, A. Parini, and F. Di Lisa, "Monoamine oxidases as sources of oxidants in the heart," Journal of Molecular and Cellular Cardiology, vol. 73, pp. 34-42, 2014.

[8] D. D. Thomas, J. L. Heinecke, L. A. Ridnour et al., "Signaling and stress: the redox landscape in NOS2 biology," Free Radical Biology and Medicine, vol. 87, pp. 204-225, 2015.

[9] K. M. Holmström and T. Finkel, "Cellular mechanisms and physiological consequences of redox-dependent signalling," Nature Reviews Molecular Cell Biology, vol. 15, no. 6, pp. 411-421, 2014.

[10] B. Halliwell, “The wanderings of a free radical," Free Radical Biology and Medicine, vol. 46, no. 5, pp. 531-542, 2009.

[11] T. A. Rando, "Oxidative stress and the pathogenesis of muscular dystrophies," American Journal of Physical Medicine \& Rehabilitation, vol. 81, no. 11, pp. S175-S186, 2002.

[12] S. Pervaiz, R. Taneja, and S. Ghaffari, "Oxidative stress regulation of stem and progenitor cells," Antioxidants and Redox Signaling, vol. 11, no. 11, pp. 2777-2789, 2009.

[13] C. Scheele, S. Nielsen, and B. K. Pedersen, "ROS and myokines promote muscle adaptation to exercise," Trends in Endocrinology and Metabolism, vol. 20, no. 3, pp. 95-99, 2009.

[14] F. McArdle, D. M. Pattwell, A. Vasilaki, A. McArdle, and M. J. Jackson, "Intracellular generation of reactive oxygen species by contracting skeletal muscle cells," Free Radical Biology and Medicine, vol. 39, no. 5, pp. 651-657, 2005.

[15] M. D. Brand and T. C. Esteves, "Physiological functions of the mitochondrial uncoupling proteins UCP2 and UCP3," Cell Metabolism, vol. 2, no. 2, pp. 85-93, 2005.

[16] R. Xia, J. A. Webb, L. L. M. Gnall, K. Cutler, and J. J. Abramson, "Skeletal muscle sarcoplasmic reticulum contains a NADHdependent oxidase that generates superoxide," American Journal of Physiology-Cell Physiology, vol. 285, no. 1, pp. C215-C221, 2003.

[17] G. K. Sakellariou, A. Vasilaki, J. Palomero et al., "Studies of mitochondrial and nonmitochondrial sources implicate nicotinamide adenine dinucleotide phosphate oxidase(s) in the increased skeletal muscle superoxide generation that occurs during contractile activity," Antioxidants and Redox Signaling, vol. 18, no. 6, pp. 603-621, 2013.

[18] Y. Hellsten-Westing, "Immunohistochemical localization of xanthine oxidase in human cardiac and skeletal muscle," Histochemistry, vol. 100, no. 3, pp. 215-222, 1993. 
[19] L. Zuo, F. L. Christofi, V. P. Wright, S. Bao, and T. L. Clanton, "Lipoxygenase-dependent superoxide release in skeletal muscle," Journal of Applied Physiology, vol. 97, no. 2, pp. 661-668, 2004.

[20] X. Zhao, E. A. Bey, F. B. Wientjes, and M. K. Cathcart, "Cytosolic phospholipase $\mathrm{A}_{2}\left(\mathrm{cPLA}_{2}\right)$ regulation of human monocyte NADPH oxidase activity: $\mathrm{CPLA}_{2}$ affects translocation but not phosphorylation of $\mathrm{p} 67^{\text {phox }}$ and $\mathrm{p} 47^{\text {phox }}$, The Journal of Biological Chemistry, vol. 277, no. 28, pp. 25385-25392, 2002.

[21] D. Nethery, L. A. Callahan, D. Stofan, R. Mattera, A. DiMarco, and G. Supinski, "PLA 2 dependence of diaphragm mitochondrial formation of reactive oxygen species," Journal of Applied Physiology, vol. 89, no. 1, pp. 72-80, 2000.

[22] M. C. Gong, S. Arbogast, Z. Guo, J. Mathenia, W. Su, and M. B. Reid, "Calcium-independent phospholipase $A_{2}$ modulates cytosolic oxidant activity and contractile function in murine skeletal muscle cells," Journal of Applied Physiology, vol. 100, no. 2, pp. 399-405, 2006.

[23] T. W. Balon and J. L. Nadler, "Nitric oxide release is present from incubated skeletal muscle preparations," Journal of Applied Physiology, vol. 77, no. 6, pp. 2519-2521, 1994.

[24] J. S. Stamler and G. Meissner, "Physiology of nitric oxide in skeletal muscle," Physiological Reviews, vol. 81, no. 1, pp. 209237, 2001.

[25] K. E. Davies and K. J. Nowak, "Molecular mechanisms of muscular dystrophies: old and new players," Nature Reviews Molecular Cell Biology, vol. 7, no. 10, pp. 762-773, 2006.

[26] A. E. H. Emery and F. Muntoni, Duchenne Muscular Dystrophy, Oxford University Press, Oxford, NY, USA, 2003.

[27] Centers for Disease Control and Prevention (CDC), "Prevalence of Duchenne/Becker muscular dystrophy among males aged 5-24 years-four states, 2007," Morbidity and Mortality Weekly Report, vol. 58, no. 40, pp. 1119-1122, 2009.

[28] E. P. Hoffman, R. H. Brown Jr., and L. M. Kunkel, "Dystrophin: the protein product of the duchenne muscular dystrophy locus," Cell, vol. 51, no. 6, pp. 919-928, 1987.

[29] J. M. Ervasti and K. P. Campbell, "Membrane organization of the dystrophin-glycoprotein complex," Cell, vol. 66, no. 6, pp. 1121-1131, 1991.

[30] M. Canton, S. Menazza, and F. Di Lisa, "Oxidative stress in muscular dystrophy: from generic evidence to specific sources and targets," Journal of Muscle Research and Cell Motility, vol. 35, no. 1, pp. 23-36, 2014.

[31] J. R. Terrill, H. G. Radley-Crabb, T. Iwasaki, F. A. Lemckert, P. G. Arthur, and M. D. Grounds, "Oxidative stress and pathology in muscular dystrophies: focus on protein thiol oxidation and dysferlinopathies," FEBS Journal, vol. 280, no. 17, pp. 4149-4164, 2013.

[32] T. A. Rando, "Role of nitric oxide in the pathogenesis of muscular dystrophies: a 'two hit' hypothesis of the cause of muscle necrosis," Microscopy Research and Technique, vol. 55, no. 4, pp. 223-235, 2001.

[33] M. C. Rodriguez and M. A. Tarnopolsky, "Patients with dystrophinopathy show evidence of increased oxidative stress," Free Radical Biology and Medicine, vol. 34, no. 9, pp. 1217-1220, 2003.

[34] N. C. Kar and C. M. Pearson, "Catalase, superoxide dismutase, glutathione reductase and thiobarbituric acid-reactive products in normal and dystrophic human muscle," Clinica Chimica Acta, vol. 94, no. 3, pp. 277-280, 1979.
[35] P. Sicinski, Y. Geng, A. S. Rydercook, E. A. Barnard, M. G. Darlison, and P. J. Barnard, "The molecular-basis of musculardystrophy in the mdx mouse-a point mutation," Science, vol. 244, pp. 1578-1580, 1989.

[36] M.-H. Disatnik, J. Dhawan, Y. Yu et al., "Evidence of oxidative stress in mdx mouse muscle: studies of the pre-necrotic state," Journal of the Neurological Sciences, vol. 161, no. 1, pp. 77-84, 1998.

[37] T. A. Rando, M.-H. Disatnik, Y. Yu, and A. Franco, "Muscle cells from mdx mice have an increased susceptibility to oxidative stress," Neuromuscular Disorders, vol. 8, no. 1, pp. 14-21, 1998.

[38] J. T. Selsby, "Increased catalase expression improves muscle function in mdx mice," Experimental Physiology, vol. 96, no. 2, pp. 194-202, 2011.

[39] J. E. Brenman, D. S. Chao, H. Xia, K. Aldape, and D. S. Bredt, "Nitric oxide synthase complexed with dystrophin and absent from skeletal muscle sarcolemma in Duchenne muscular dystrophy," Cell, vol. 82, no. 5, pp. 743-752, 1995.

[40] R. J. L. F. Lemmers, P. J. van der Vliet, R. Klooster et al., "A unifying genetic model for facioscapulohumeral muscular dystrophy," Science, vol. 329, no. 5999, pp. 1650-1653, 2010.

[41] A. Turki, M. Hayot, G. Carnac et al., "Functional muscle impairment in facioscapulohumeral muscular dystrophy is correlated with oxidative stress and mitochondrial dysfunction," Free Radical Biology and Medicine, vol. 53, no. 5, pp. 1068-1079, 2012.

[42] R. Han and K. P. Campbell, "Dysferlin and muscle membrane repair," Current Opinion in Cell Biology, vol. 19, no. 4, pp. 409416, 2007.

[43] E. Bertini and G. Pepe, "Collagen type VI and related disorders: bethlem myopathy and Ullrich scleroatonic muscular dystrophy," European Journal of Paediatric Neurology, vol. 6, no. 4, pp. 193-198, 2002.

[44] E. Sorato, S. Menazza, A. Zulian et al., "Monoamine oxidase inhibition prevents mitochondrial dysfunction and apoptosis in myoblasts from patients with collagen VI myopathies," Free Radical Biology and Medicine, vol. 75, pp. 40-47, 2014.

[45] A. Helbling-Leclerc, X. Zhang, H. Topaloglu et al., "Mutations in the laminin $\alpha 2$-chain gene (LAMA2) cause merosin-deficient congenital muscular dystrophy," Nature Genetics, vol. 11, no. 2, pp. 216-218, 1995.

[46] V. Pekovic, I. Gibbs-Seymour, E. Markiewicz et al., "Conserved cysteine residues in the mammalian lamin A tail are essential for cellular responses to ROS generation," Aging Cell, vol. 10, no. 6, pp. 1067-1079, 2011.

[47] A. Franco Jr. and J. B. Lansman, "Calcium entry through stretchinactivated ion channels in mdx myotubes," Nature, vol. 344, no. 6267, pp. 670-673, 1990.

[48] P. S. Brookes and V. M. Darley-Usmar, "Role of calcium and superoxide dismutase in sensitizing mitochondria to peroxynitrite-induced permeability transition," American Journal of Physiology-Heart and Circulatory Physiology, vol. 286, no. 1, pp. H39-H46, 2004.

[49] A. R. Burr and J. D. Molkentin, "Genetic evidence in the mouse solidifies the calcium hypothesis of myofiber death in muscular dystrophy," Cell Death and Differentiation, vol. 22, no. 9, pp. 1402-1412, 2015.

[50] N. Bakkar and D. C. Guttridge, "NF- $\kappa$ B signaling: a tale of two pathways in skeletal myogenesis," Physiological Reviews, vol. 90, no. 2, pp. 495-511, 2010. 
[51] A. Kumar and A. M. Boriek, "Mechanical stress activates the nuclear factor-kappaB pathway in skeletal muscle fibers: a possible role in Duchenne muscular dystrophy," The FASEB Journal, vol. 17, no. 3, pp. 386-396, 2003.

[52] S. Acharyya, S. A. Villalta, N. Bakkar et al., "Interplay of IKK/NF- $\kappa$ B signaling in macrophages and myofibers promotes muscle degeneration in Duchenne muscular dystrophy," Journal of Clinical Investigation, vol. 117, no. 4, pp. 889-901, 2007.

[53] S. Messina, A. Bitto, M. Aguennouz et al., "Nuclear factor kappa-B blockade reduces skeletal muscle degeneration and enhances muscle function in Mdx mice," Experimental Neurology, vol. 198, no. 1, pp. 234-241, 2006.

[54] N. P. Whitehead, E. W. Yeung, and D. G. Allen, "Muscle damage in $\mathrm{mdx}$ (dystrophic) mice: role of calcium and reactive oxygen species," Clinical and Experimental Pharmacology and Physiology, vol. 33, no. 7, pp. 657-662, 2006.

[55] J. D. Proto, Y. Tang, A. Lu et al., "NF- $\kappa$ B inhibition reveals a novel role for HGF during skeletal muscle repair," Cell Death and Disease, vol. 6, no. 4, Article ID e1730, 2015.

[56] C. Vercherat, T.-K. Chung, S. Yalcin et al., "Stral3 regulates oxidative stress mediated skeletal muscle degeneration," Human Molecular Genetics, vol. 18, no. 22, pp. 4304-4316, 2009.

[57] N. Mizushima and M. Komatsu, "Autophagy: renovation of cells and tissues," Cell, vol. 147, no. 4, pp. 728-741, 2011.

[58] G. Kroemer and E. White, "Autophagy for the avoidance of degenerative, inflammatory, infectious, and neoplastic disease," Current Opinion in Cell Biology, vol. 22, no. 2, pp. 121-123, 2010.

[59] J. Kim, M. Kundu, B. Viollet, and K.-L. Guan, "AMPK and mTOR regulate autophagy through direct phosphorylation of Ulk1," Nature Cell Biology, vol. 13, no. 2, pp. 132-141, 2011.

[60] M. Sandri, "Autophagy in health and disease. 3. Involvement of autophagy in muscle atrophy," The American Journal of Physiology-Cell Physiology, vol. 298, no. 6, pp. C1291-C1297, 2010.

[61] J. Zhao, J. J. Brault, A. Schild et al., "FoxO3 coordinately activates protein degradation by the autophagic/lysosomal and proteasomal pathways in atrophying muscle cells," Cell Metabolism, vol. 6, no. 6, pp. 472-483, 2007.

[62] E. Masiero, L. Agatea, C. Mammucari et al., "Autophagy is required to maintain muscle mass," Cell Metabolism, vol. 10, no. 6, pp. 507-515, 2009.

[63] M. Sandri, L. Coletto, P. Grumati, and P. Bonaldo, "Misregulation of autophagy and protein degradation systems in myopathies and muscular dystrophies," Journal of Cell Science, vol. 126, no. 23, pp. 5325-5333, 2013.

[64] M. Pauly, F. Daussin, Y. Burelle et al., "AMPK activation stimulates autophagy and ameliorates muscular dystrophy in the mdx mouse diaphragm," The American Journal of Pathology, vol. 181, no. 2, pp. 583-592, 2012.

[65] C. De Palma, F. Morisi, S. Cheli et al., "Autophagy as a new therapeutic target in Duchenne muscular dystrophy," Cell Death and Disease, vol. 3, article e418, 2012.

[66] P. Grumati, L. Coletto, P. Sabatelli et al., "Autophagy is defective in collagen VI muscular dystrophies, and its reactivation rescues myofiber degeneration," Nature Medicine, vol. 16, no. 11, pp. 1313-1320, 2010.

[67] P. Grumati, L. Coletto, M. Sandri, and P. Bonaldo, "Autophagy induction rescues muscular dystrophy," Autophagy, vol. 7, no. 4, pp. 426-428, 2011.

[68] V. Carmignac, M. Svensson, Z. Körner et al., "Autophagy is increased in laminin $\alpha 2$ chain-deficient muscle and its inhibition improves muscle morphology in a mouse model of MDC1A," Human Molecular Genetics, vol. 20, no. 24, pp. 48914902, 2011.

[69] R. Pal, M. Palmieri, J. A. Loehr et al., "Src-dependent impairment of autophagy by oxidative stress in a mouse model of Duchenne muscular dystrophy," Nature Communications, vol. 5, article 4425, 2014.

[70] J. Lee, S. Giordano, and J. Zhang, "Autophagy, mitochondria and oxidative stress: cross-talk and redox signalling," Biochemical Journal, vol. 441, no. 2, pp. 523-540, 2012.

[71] C. N. Young, A. Sinadinos, A. Lefebvre et al., "A novel mechanism of autophagic cell death in dystrophic muscle regulated by P2RX7 receptor large-pore formation and HSP90," Autophagy, vol. 11, no. 1, pp. 113-130, 2014.

[72] P. B. Gurpur, J. Liu, D. J. Burkin, and S. J. Kaufman, "Valproic acid activates the PI3K/Akt/mTOR pathway in muscle and ameliorates pathology in a mouse model of Duchenne muscular dystrophy," American Journal of Pathology, vol. 174, no. 3, pp. 999-1008, 2009.

[73] X. Sui, J. Zhu, J. Zhou et al., "Epigenetic modifications as regulatory elements of autophagy in cancer," Cancer Letters, vol. 360, no. 2, pp. 106-113, 2015.

[74] H. L. In, L. Cao, R. Mostoslavsky et al., "A role for the NADdependent deacetylase Sirtl in the regulation of autophagy," Proceedings of the National Academy of Sciences of the United States of America, vol. 105, no. 9, pp. 3374-3379, 2008.

[75] J. G. Ryall, S. Dell'Orso, A. Derfoul et al., “The NAD ${ }^{+}$-dependent SIRT1 deacetylase translates a metabolic switch into regulatory epigenetics in skeletal muscle stem cells," Cell Stem Cell, vol. 16, no. 2, pp. 171-183, 2015.

[76] T. von Zglinicki, "Oxidative stress shortens telomeres," Trends in Biochemical Sciences, vol. 27, no. 7, pp. 339-344, 2002.

[77] L. Liu, J. R. Trimarchi, P. J. S. Smith, and D. L. Keefe, "Mitochondrial dysfunction leads to telomere attrition and genomic instability," Aging Cell, vol. 1, no. 1, pp. 40-46, 2002.

[78] A. T. Ludlow, E. E. Spangenburg, E. R. Chin, W.-H. Cheng, and S. M. Roth, "Telomeres shorten in response to oxidative stress in mouse skeletal muscle fibers," Journals of Gerontology-Series A: Biological Sciences and Medical Sciences, vol. 69, no. 7, pp. 821830, 2014.

[79] S. Decary, V. Mouly, C. Ben Hamida, A. Sautet, J. P. Barbet, and G. S. Butler-Browne, "Replicative potential and telomere length in human skeletal muscle: implications for satellite cellmediated gene therapy," Human Gene Therapy, vol. 8, no. 12, pp. 1429-1438, 1997.

[80] H. M. Blau, C. Webster, and G. K. Pavlath, "Defective myoblasts identified in Duchenne muscular dystrophy," Proceedings of the National Academy of Sciences of the United States of America, vol. 80, no. 15, pp. 4856-4860, 1983.

[81] V. Renault, G. Piron-Hamelin, C. Forestier et al., "Skeletal muscle regeneration and the mitotic clock," Experimental Gerontology, vol. 35, no. 6-7, pp. 711-719, 2000.

[82] F. Mourkioti, J. Kustan, P. Kraft et al., "Role of telomere dysfunction in cardiac failure in Duchenne muscular dystrophy," Nature Cell Biology, vol. 15, no. 8, pp. 895-904, 2013.

[83] A. Sacco, F. Mourkioti, R. Tran et al., "Short telomeres and stem cell exhaustion model duchenne muscular dystrophy in mdx/mTR mice," Cell, vol. 143, no. 7, pp. 1059-1071, 2010.

[84] A. Lu, M. Poddar, Y. Tang et al., "Rapid depletion of muscle progenitor cells in dystrophic mdx/utrophin ${ }^{-}$mice," Human Molecular Genetics, vol. 23, no. 18, Article ID ddu194, pp. 47864800, 2014. 
[85] J. L. Jacobs, K. Kieboom, S. Marino, R. A. DePinho, and M. van Lohuizen, "The oncogene and Polycomb-group gene bmi1 regulates cell proliferation and senescence through the ink4a locus," Nature, vol. 397, no. 6715, pp. 164-168, 1999.

[86] V. Di Foggia, X. Zhang, D. Licastro et al., "Bmil enhances skeletal muscle regeneration through MT1-mediated oxidative stress protection in a mouse model of dystrophinopathy," Journal of Experimental Medicine, vol. 211, no. 13, pp. 2617-2633, 2014.

[87] A. M. Y. Shum, T. Mahendradatta, R. J. Taylor et al., "Disruption of $\mathrm{MEF} 2 \mathrm{C}$ signaling and loss of sarcomeric and mitochondrial integrity in cancer-induced skeletal muscle wasting," Aging, vol. 4, no. 2, pp. 133-143, 2012.

[88] K. J. A. Davies, A. T. Quintanilha, G. A. Brooks, and L. Packer, "Free radicals and tissue damage produced by exercise," Biochemical and Biophysical Research Communications, vol. 107, no. 4, pp. 1198-1205, 1982.

[89] A. P. Russell, J. Feilchenfeldt, S. Schreiber et al., "Endurance training in humans leads to fiber type-specific increases in levels of peroxisome proliferator-activated receptor-gamma coactivator-1 and peroxisome proliferator-activated receptoralpha in skeletal muscle," Diabetes, vol. 52, no. 12, pp. 2874-2881, 2003.

[90] M. C. Chan and Z. Arany, "The many roles of PGC-1 $\alpha$ in muscle-recent developments," Metabolism: Clinical and Experimental, vol. 63, no. 4, pp. 441-451, 2014.

[91] I. Irrcher, V. Ljubicic, and D. A. Hood, "Interactions between ROS and AMP kinase activity in the regulation of PGC- $1 \alpha$ transcription in skeletal muscle cells," The American Journal of Physiology-Cell Physiology, vol. 296, no. 1, pp. C116-C123, 2009.

[92] M. E. Sandström, S.-J. Zhang, J. Bruton et al., "Role of reactive oxygen species in contraction-mediated glucose transport in mouse skeletal muscle," The Journal of Physiology, vol. 575, no. 1, pp. 251-262, 2006.

[93] T. Vassilakopoulos, M.-H. Karatza, P. Katsaounou, A. Kollintza, S. Zakynthinos, and C. Roussos, "Antioxidants attenuate the plasma cytokine response to exercise in humans," Journal of Applied Physiology, vol. 94, no. 3, pp. 1025-1032, 2003.

[94] C. P. Fischer, P. Plomgaard, A. K. Hansen, H. Pilegaard, B. Saltin, and B. K. Pedersen, "Endurance training reduces the contraction-induced interleukin-6 mRNA expression in human skeletal muscle," The American Journal of PhysiologyEndocrinology and Metabolism, vol. 287, no. 6, pp. E1189-E1194, 2004.

[95] M. Ristow, K. Zarse, A. Oberbach et al., "Antioxidants prevent health-promoting effects of physical exercise in humans," Proceedings of the National Academy of Sciences of the United States of America, vol. 106, no. 21, pp. 8665-8670, 2009.

[96] S. Mason and G. D. Wadley, "Skeletal muscle reactive oxygen species: a target of good cop/bad cop for exercise and disease," Redox Report, vol. 19, no. 3, pp. 97-106, 2014.

[97] R. Burdi, J.-F. Rolland, B. Fraysse et al., "Multiple pathological events in exercised dystrophic $\mathrm{mdx}$ mice are targeted by pentoxifylline: outcome of a large array of in vivo and ex vivo tests," Journal of Applied Physiology, vol. 106, no. 4, pp. 1311-1324, 2009.

[98] D. M. Escolar, A. Zimmerman, T. Bertorini et al., "Pentoxifylline as a rescue treatment for DMD: a randomized double-blind clinical trial," Neurology, vol. 78, no. 12, pp. 904-913, 2012.

[99] A. De Luca, "Pre-clinical drug tests in the mdx mouse as a model of dystrophinopathies: an overview," Acta Myologica, vol. 31, pp. 40-47, 2012.
[100] H. G. Radley, A. De Luca, G. S. Lynch, and M. D. Grounds, "Duchenne muscular dystrophy: focus on pharmaceutical and nutritional interventions," International Journal of Biochemistry and Cell Biology, vol. 39, no. 3, pp. 469-477, 2007.

[101] Y. Pan, C. Chen, Y. Shen et al., "Curcumin alleviates dystrophic muscle pathology in mdx mice," Molecules and Cells, vol. 25, no. 4, pp. 531-537, 2008.

[102] L. H. Moraes, R. R. de Burgos, A. B. Macedo, T. de Almeida Hermes, F. M. de Faria, and E. Minatel, "Reduction of oxidative damage and inflammatory response in the diaphragm muscle of mdx mice using iron chelator deferoxamine," Biological Trace Element Research, vol. 167, no. 1, pp. 115-120, 2015.

[103] D. G. Allen, N. P. Whitehead, and E. W. Yeung, "Mechanisms of stretch-induced muscle damage in normal and dystrophic muscle: role of ionic changes," Journal of Physiology, vol. 567, no. 3, pp. 723-735, 2005.

[104] F. Altamirano, D. Valladares, C. Henríquez-Olguín et al., "Nifedipine treatment reduces resting calcium concentration, oxidative and apoptotic gene expression, and improves muscle function in dystrophic mdx mice," PLoS ONE, vol. 8, no. 12, Article ID e81222, 2013.

[105] A. Cozzoli, B. Nico, V. T. Sblendorio et al., "Enalapril treatment discloses an early role of angiotensin II in inflammationand oxidative stress-related muscle damage in dystrophic $\mathrm{mdx}$ mice," Pharmacological Research, vol. 64, no. 5, pp. 482-492, 2011.

[106] Y. Nakae, O. M. Dorchies, P. J. Stoward, B. F. Zimmermann, C. Ritter, and U. T. Ruegg, "Quantitative evaluation of the beneficial effects in the mdx mouse of epigallocatechin gallate, an antioxidant polyphenol from green tea," Histochemistry and Cell Biology, vol. 137, no. 6, pp. 811-827, 2012.

[107] O. M. Dorchies, S. Wagner, O. Vuadens et al., "Green tea extract and its major polyphenol (-)-epigallocatechin gallate improve muscle function in a mouse model for Duchenne muscular dystrophy," American Journal of Physiology: Cell Physiology, vol. 290, no. 2, pp. C616-C625, 2006.

[108] Y. Hibaoui, J. Reutenauer-Patte, O. Patthey-Vuadens, U. T. Ruegg, and O. M. Dorchies, "Melatonin improves muscle function of the dystrophic $m d x^{5 \mathrm{Cv}}$ mouse, a model for Duchenne muscular dystrophy," Journal of Pineal Research, vol. 51, no. 2, pp. 163-171, 2011.

[109] M. Chahbouni, G. Escames, C. Venegas et al., "Melatonin treatment normalizes plasma pro-inflammatory cytokines and nitrosative/oxidative stress in patients suffering from Duchenne muscular dystrophy," Journal of Pineal Research, vol. 48, no. 3, pp. 282-289, 2010.

[110] M. Chahbouni, G. Escames, L. C. López et al., "Melatonin treatment counteracts the hyperoxidative status in erythrocytes of patients suffering from Duchenne muscular dystrophy," Clinical Biochemistry, vol. 44, no. 10-11, pp. 853-858, 2011.

[111] G. M. Buyse, N. Goemans, M. van den Hauwe et al., "Idebenone as a novel, therapeutic approach for Duchenne muscular dystrophy: results from a 12 month, double-blind, randomized placebo-controlled trial," Neuromuscular Disorders, vol. 21, no. 6, pp. 396-405, 2011.

[112] G. M. Buyse, T. Voit, U. Schara et al., "Efficacy of idebenone on respiratory function in patients with Duchenne muscular dystrophy not using glucocorticoids (DELOS): a double-blind randomised placebo-controlled phase 3 trial," The Lancet, vol. 385, no. 9979, pp. 1748-1757, 2015.

[113] G. M. Buyse, G. Van Der Mieren, M. Erb et al., "Long-term blinded placebo-controlled study of SNT-MC17/idebenone in 
the dystrophin deficient $m d x$ mouse: cardiac protection and improved exercise performance," European Heart Journal, vol. 30, no. 1, pp. 116-124, 2009.

[114] G. M. Buyse, N. Goemans, M. Van Den Hauwe, and T. Meier, "Effects of glucocorticoids and idebenone on respiratory function in patients with duchenne muscular dystrophy," Pediatric Pulmonology, vol. 48, no. 9, pp. 912-920, 2013.

[115] S. Eghtesad, S. Jhunjhunwala, S. R. Little, and P. R. Clemens, "Rapamycin ameliorates dystrophic phenotype in $\mathrm{mdx}$ mouse skeletal muscle," Molecular Medicine, vol. 17, no. 9-10, pp. 917924, 2011.

[116] G. Pallafacchina, E. Calabria, A. L. Serrano, J. M. Kalhovde, and S. Schiaffino, "A protein kinase B-dependent and rapamycinsensitive pathway controls skeletal muscle growth but not fiber type specification," Proceedings of the National Academy of Sciences of the United States of America, vol. 99, no. 14, pp. 92139218, 2002.

[117] K. P. Bibee, Y.-J. Cheng, J. K. Ching et al., "Rapamycin nanoparticles target defective autophagy in muscular dystrophy to enhance both strength and cardiac function," The FASEB Journal, vol. 28, no. 5, pp. 2047-2061, 2014.

[118] K. T. Howitz, K. J. Bitterman, H. Y. Cohen et al., "Small molecule activators of sirtuins extend Saccharomyces cerevisiae lifespan," Nature, vol. 425, no. 6954, pp. 191-196, 2003.

[119] Y. S. Hori, A. Kuno, R. Hosoda et al., "Resveratrol ameliorates muscular pathology in the dystrophic $m d x$ mouse, a model for Duchenne muscular dystrophy," Journal of Pharmacology and Experimental Therapeutics, vol. 338, no. 3, pp. 784-794, 2011.

[120] B. S. Gordon, D. C. Delgado-Diaz, J. Carson, R. Fayad, L. B. Wilson, and M. C. Kostek, "Resveratrol improves muscle function but not oxidative capacity in young $\mathrm{mdx}$ mice," Canadian Journal of Physiology and Pharmacology, vol. 92, no. 3, pp. 243-251, 2014.

[121] J. M. Lawler, W. S. Barnes, G. Wu, W. Song, and S. Demaree, "Direct antioxidant properties of creatine," Biochemical and Biophysical Research Communications, vol. 290, no. 1, pp. 47-52, 2002.

[122] A.-C. Passaquin, M. Renard, L. Kay et al., "Creatine supplementation reduces skeletal muscle degeneration and enhances mitochondrial function in mdx mice," Neuromuscular Disorders, vol. 12, no. 2, pp. 174-182, 2002.

[123] M. A. Tarnopolsky, D. J. Mahoney, J. Vajsar et al., "Creatine monohydrate enhances strength and body composition in Duchenne muscular dystrophy," Neurology, vol. 62, no. 10, pp. 1771-1777, 2004.

[124] B. Banerjee, U. Sharma, K. Balasubramanian, M. Kalaivani, V. Kalra, and N. R. Jagannathan, "Effect of creatine monohydrate in improving cellular energetics and muscle strength in ambulatory Duchenne muscular dystrophy patients: a randomized, placebo-controlled ${ }^{31} \mathrm{P}$ MRS study," Magnetic Resonance Imaging, vol. 28, no. 5, pp. 698-707, 2010.

[125] J. B. Dupont, B. Tournaire, C. Georger et al., "Short-lived recombinant adeno-associated virus transgene expression in dystrophic muscle is associated with oxidative damage to transgene mRNA," Molecular Therapy-Methods \& Clinical Development, vol. 2, Article ID 15010, 2015.

[126] J.-T. Vilquin, C. Catelain, and K. Vauchez, "Cell therapy for muscular dystrophies: advances and challenges," Current Opinion in Organ Transplantation, vol. 16, no. 6, pp. 640-649, 2011. 


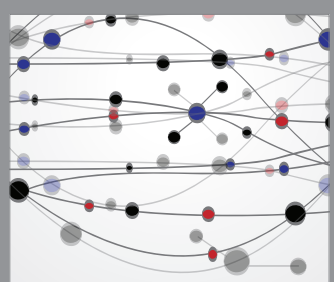

The Scientific World Journal
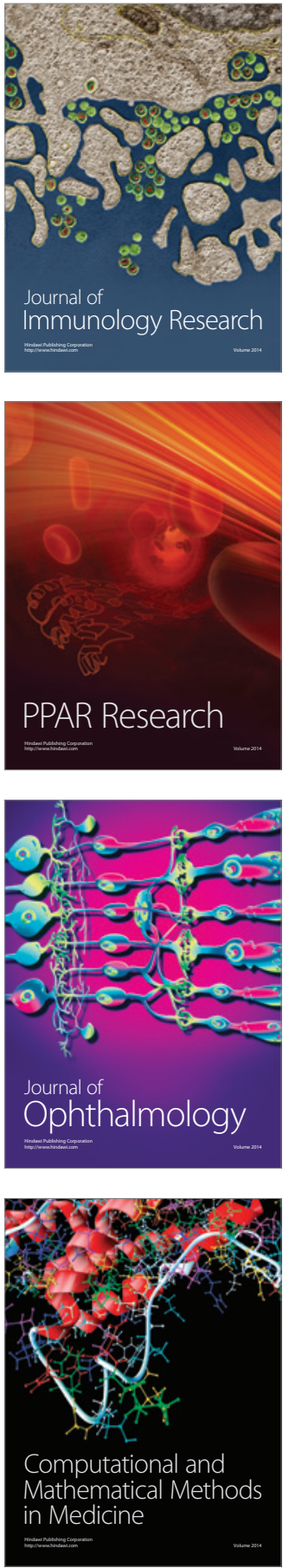

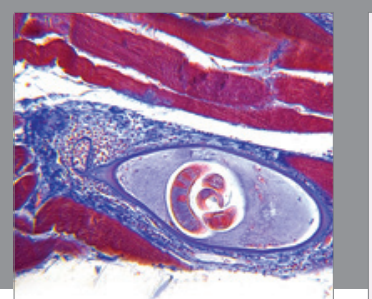

Gastroenterology Research and Practice

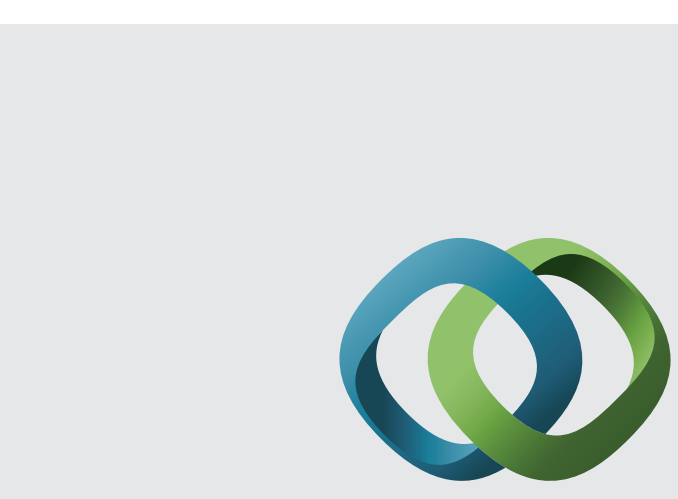

\section{Hindawi}

Submit your manuscripts at

http://www.hindawi.com
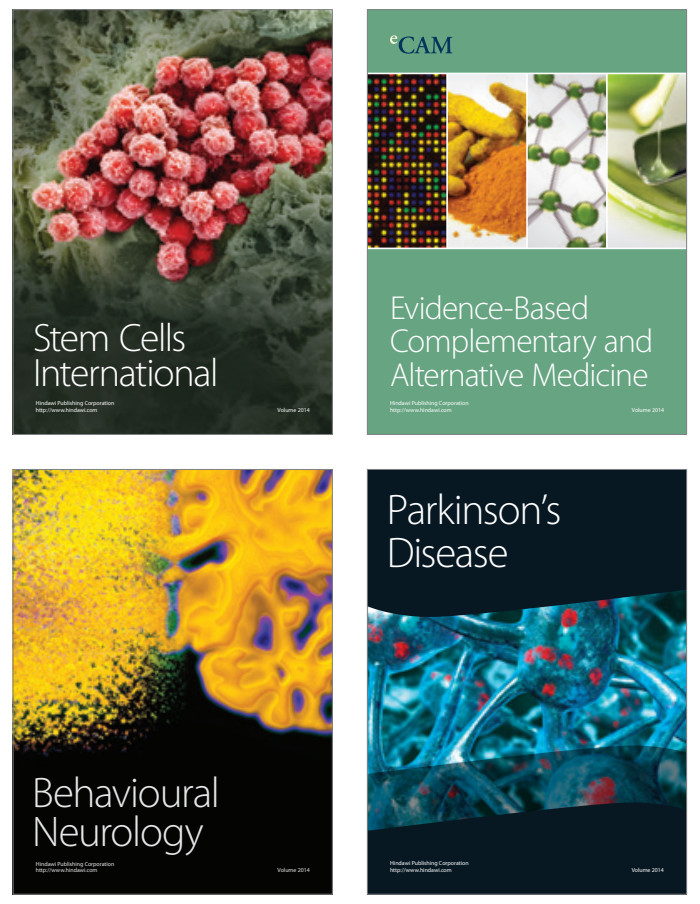
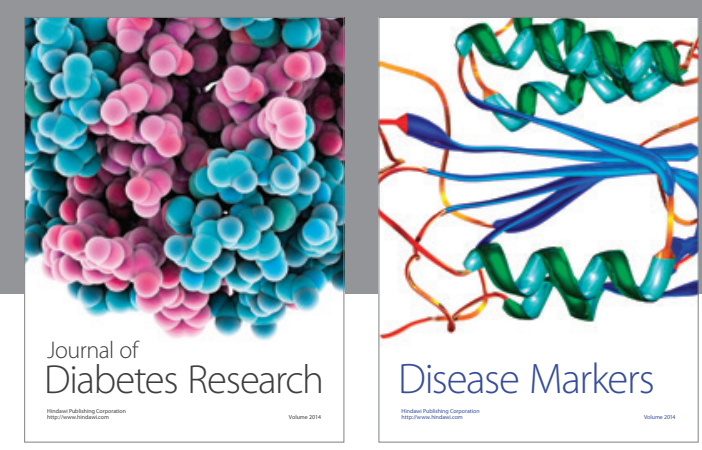

Disease Markers
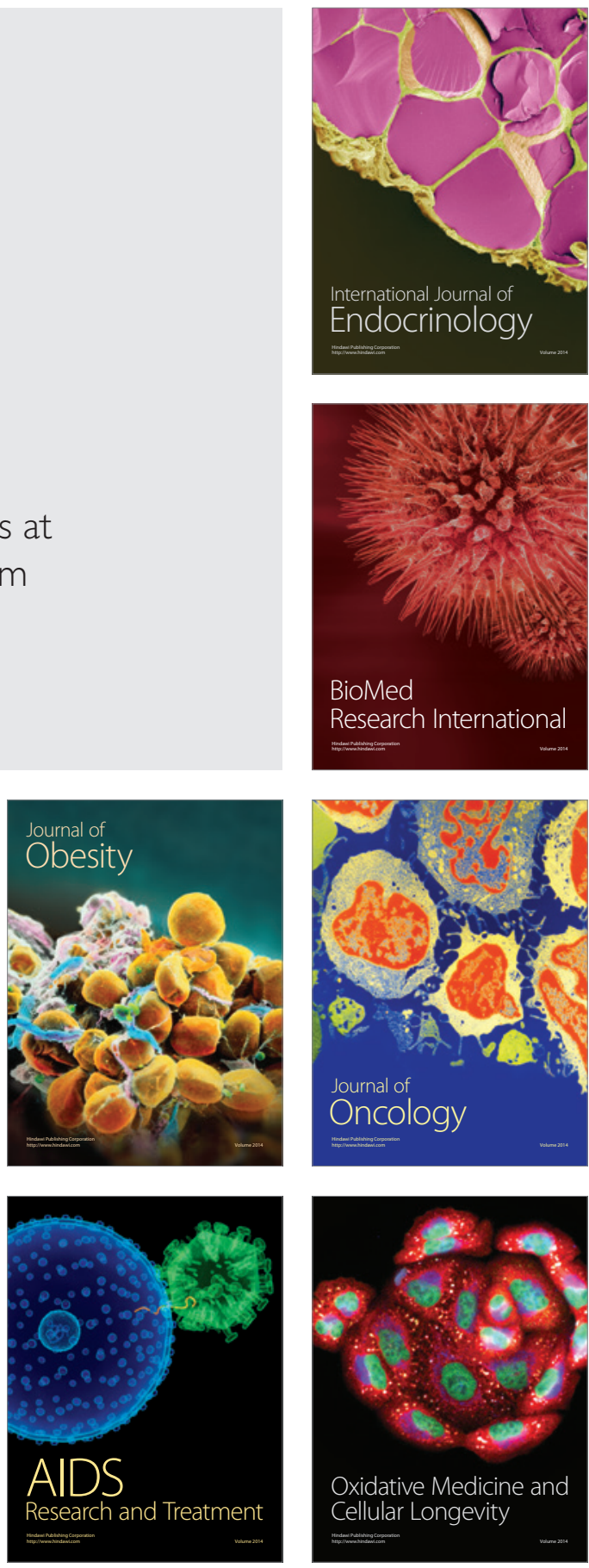